\title{
Effects of returns on composition, microstructure and mechanical properties of GH4169 superalloy
}

\author{
Yong-liang Pu ${ }^{1}$, *Sheng-zhong Kou ${ }^{1,2}$, Zhi-dong Zhang ${ }^{1}$, Tian-wen Dong ${ }^{1}$, Xiao-fan Guo ${ }^{1}$, and Hong-Xia Qu ${ }^{1}$ \\ 1. State Key Laboratory of Advanced Processing and Recycling of Nonferrous Metals, Lanzhou University of Technology, Lanzhou 730050, China; \\ 2. Key Laboratory of Non-ferrous Metal Alloys and Processing of the Ministry of Education, Lanzhou University of Technology, Lanzhou 730050, \\ China
}

\begin{abstract}
To recycle the returned alloy effectively, effects of returns proportion on alloy composition, microstructure and compression properties of superalloy GH4169 were studied by means of scanning electron microscopy (SEM), energy dispersive spectroscopy (EDS) and thermal-mechanical simulator. The results show that returns addition has no significant effect on the main alloy elements content and the principle precipitates, but increases the volume fraction of $\mathrm{Al}_{2} \mathrm{O}_{3}$ inclusions, resulting in the increase of oxygen level of $\mathrm{GH} 4169$ alloy. Returns addition does not change the elastic and plastic deformation process at room temperature or at $1,150{ }^{\circ} \mathrm{C}$, but high returns proportion GH4169 alloy shows improved compression strength and yield strength. The alloy with $100 \%$ returns shows a maximum compression strength $1,153.45 \mathrm{MPa}$ at room temperature, while the alloy with $80 \%$ returns has a maximum value $69.3 \mathrm{MPa}$ at $1,150{ }^{\circ} \mathrm{C}$. Returns addition increases fluctuation range and reduces the stability of yield strength and compression strength of $\mathrm{GH} 4169$ alloy at room temperature. It is noted that the volume fraction and the size of $\mathrm{Al}_{2} \mathrm{O}_{3}$, and the fraction of Laves phase reach their maximum values in the GH4169 alloy with $60 \%$ returns, which exhibits maximum yield strength of $516.65 \mathrm{MPa}$ at room temperature and $62.17 \mathrm{MPa}$ at $1,150{ }^{\circ} \mathrm{C}$.
\end{abstract}

Key words: superalloy; returns proportion; composition; microstructure; mechanical properties

CLC numbers: TG146.1 5 Document code: A Article ID: 1672-6421(2017)04-244-07

$\mathrm{T}$ he Ni-base superalloy has performed well as gas turbine blade and disc materials in aircraft, automobile, energy and nuclear industry because of their excellent creep strength, rupture ductility, thermal fatigue and oxidation resistance as well as microstructure stability ${ }^{[1]}$. However, the final products of superalloy components take just 30 percent in virgin alloy total production, which creates a massive amount of returns alloy and leads to a serious waste of noble metal ${ }^{[2]}$. To recycle the returns alloy, it is necessary to uncover effects of returns addition on the composition, microstructure and mechanical properties of superalloy.

Because many oxide and nitride inclusions are brought in during the casting process, the content of oxygen and nitrogen increases. These oxides and nitrines would increase the amount of microporosity and reduce the mechanical properties, such as ductility, rupture life

\section{*Sheng-zhong Kou}

Male, born in 1962, Professor. His research interests mainly focus on the preparation and properties of cast alloys.

E-mail: koushengzhong@163.com

Received: 2016-10-09; Accepted: 2017-03-06 and fatigue strength of the alloy ${ }^{[3-8]}$. Some similar conclusions are drawn for the superalloy with returns addition. For K465 alloy, the compositions of the alloy with different proportions of returns are similar to the virgin alloy; the returns addition has no obvious effect on $\gamma^{\prime}$ phase, but increases the amount of microporosity, which decreases the high temperature stress-rupture life and tensile elongation at room temperature ${ }^{[9]}$. For K640S alloy, the nitride content increases obviously in returns added alloy, which leads to a thicker dendrite structure and the larger number of microporosity than virgin alloy. The tensile strength, stress-rupture life and the creep strength are reduced by returns addition ${ }^{[2]}$. For K4002 alloy, returns addition would decrease the stressrupture life at intermediate temperature, because the content of the oxide inclusions increases ${ }^{[10]}$. As for K44 alloy, the high content of nitrogen and oxygen in returns alloy induce the increment of $\gamma+\gamma^{\prime}$ eutectics, the increase of inclusions, and the agglomeration of carbides, which accordingly accelerate the initiation and the propagation of the thermal fatigue crack ${ }^{[11]}$. With the increase of returns proportion, oxygen and nitrogen levels increase, and more inclusions are brought into K414 alloy ${ }^{[12]}$. 
These studies metioned above uncovered the influences of returns proportion on some cast superalloy. However, to the significant widely used superalloy GH4169, the influence of returns is still not clear. In this study, by adding various proportions of returns in GH4169 alloy, effects of returns on chemical composition, microstructure and mechanical properties of superalloy GH4169 were examined.

\section{Experimental procedure}

GH4169 alloy with various returns proportions of $20 \%, 40 \%$, $60 \%, 80 \%$ and $100 \%$, respectively, were remelted in a cold crucible induction furnace, holding $60 \mathrm{~s}$ and cast into rod samples ( $\Phi 6 \mathrm{~mm}$ ) by vacuum suction casting process. Compression properties tests were carried out on a WD-100D universal testing machine at room temperature, and on a Gleeble-3500 ThermalMechanical Simulator at $1,150{ }^{\circ} \mathrm{C}$. The compression rate was $0.54 \mathrm{~mm} \bullet \mathrm{min}^{-1}$. Each high temperature test sample was heated to $1,150{ }^{\circ} \mathrm{C}$ at $5{ }^{\circ} \mathrm{C} \cdot \mathrm{s}^{-1}$ and held for $60 \mathrm{~s}$ in the atmosphere of argon. When the strain reached 0.73 , the test was finished and then the samples were water quenched. The precipitates were characterized by a D8-Advace X-ray diffractometer (XRD) with $\mathrm{Cu} \mathrm{Ka}$ radiation. The samples for microstructure observation were mechanically polished and etched in a solution of $1.5 \mathrm{ml}$ $\mathrm{CuSO}_{4}+40 \mathrm{ml} \mathrm{HCl}+20 \mathrm{ml} \mathrm{C}_{2} \mathrm{H}_{5} \mathrm{OH}$ at room temperature, then the microstructure was observed by a Quanta FEG 450 scanning electron microscopy (SEM). The area of $\mathrm{Al}_{2} \mathrm{O}_{3}$ inclusion and Laves phase were measured with Image-Pro Plus 6.0 software. The diameter of $\mathrm{Al}_{2} \mathrm{O}_{3}$ inclusion could be calculated by the equation:

$$
D=2 \sqrt{S / \pi}
$$

where $S$ is the measured area of $\mathrm{Al}_{2} \mathrm{O}_{3}$ inclusion, $D$ is the diameter of $\mathrm{Al}_{2} \mathrm{O}_{3}$ inclusion. The volume fractions of $\mathrm{Al}_{2} \mathrm{O}_{3}$ inclusion and Laves phase were calculated based on the area fraction. Chemical compositions were analyzed with energy disperse X-ray spectroscopy (EDS) in positions as shown in Fig. 1. The composition of the alloy, the $\gamma$ and Laves phases are the average values on 5 measurements. Oxygen and nitrogen contents were measured using a LECO ONH836 experimental analyzer.

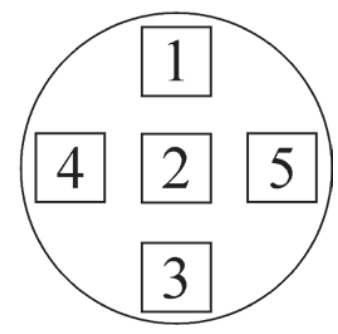

Fig. 1: Statistical regions of composition on cross section

\section{Results and discussion}

\subsection{Effects of returns addition on alloy composition}

The nominal and experimental compositions of GH4169 alloy with various proportions of returns are given in Table 1. The main element contents in the returns added alloy are still in the range of nominal composition, except for $\mathrm{Nb}$ and Ti in the alloy with $20 \%$ and $60 \%$ returns addition. This indicates that returns addition does not obviously change the main components content. $\mathrm{Nb}$ and $\mathrm{Ti}$ tend to segregate in interdendritic regions, forming Laves phase ${ }^{[13,14]}$, which will cause composition fluctuation in a nearby region.

Table 1: Chemical compositions of GH4169 samples with various returns proportion (mass\%)

\begin{tabular}{|c|c|c|c|c|c|c|c|c|}
\hline $\begin{array}{l}\text { Returns } \\
\text { proportion }\end{array}$ & $\mathrm{Cr}$ & $\mathbf{N i}$ & Mo & Al & $\mathrm{Ti}$ & $\mathrm{Fe}$ & $\mathrm{Nb}$ & $\begin{array}{l}\text { Other } \\
\text { elements }\end{array}$ \\
\hline 0 & 19.28 & 53.96 & 2.75 & 0.45 & 0.75 & 16.28 & 4.74 & 1.79 \\
\hline 20 & 19.96 & 52.93 & 2.85 & 0.49 & 0.65 & 17.55 & 3.60 & 1.96 \\
\hline 40 & 18.53 & 52.46 & 2.87 & 0.49 & 0.87 & 16.06 & 5.17 & 1.05 \\
\hline 60 & 20.28 & 53.24 & 3.00 & 0.56 & 0.62 & 17.84 & 3.38 & 1.07 \\
\hline 80 & 19.39 & 53.60 & 2.92 & 0.59 & 0.89 & 16.62 & 5.00 & 0.99 \\
\hline 100 & 19.67 & 53.08 & 3.02 & 0.57 & 0.84 & 17.02 & 4.53 & 1.28 \\
\hline Nominal ${ }^{[1]}$ & $17-21$ & $50-55$ & $2.8-3.3$ & $0.3-0.7$ & $0.75-1.15$ & $11.2-24.4$ & $4.75-5.5$ & - \\
\hline
\end{tabular}

The compositions of $\gamma$ and Laves phases in GH4169 alloy with various proportions of returns are shown in Fig. 2. The main elements are divided into three groups. $\mathrm{Ni}, \mathrm{Cr}$ and $\mathrm{Fe}$ are $\gamma$ phase constitute elements, which means that the content of these elements in $\gamma$ phase are much higher than in Laves phase, while $\mathrm{Nb}$, Mo and Ti elements mainly segregate in Laves phase. The element $\mathrm{Al}$ does not involve segregating either in $\gamma$ phase or in Laves phase. It is clear that returns addition has no significant effect on the content of main alloy elements in matrix $\gamma$ phase and Laves phase.

The content of oxygen and nitrogen in GH4169 alloy with different returns addition amounts is shown in Fig. 3. It is clear that returns addition increases the level of oxygen and nitrogen in GH4169 alloy, which is consistent with the results obtained 

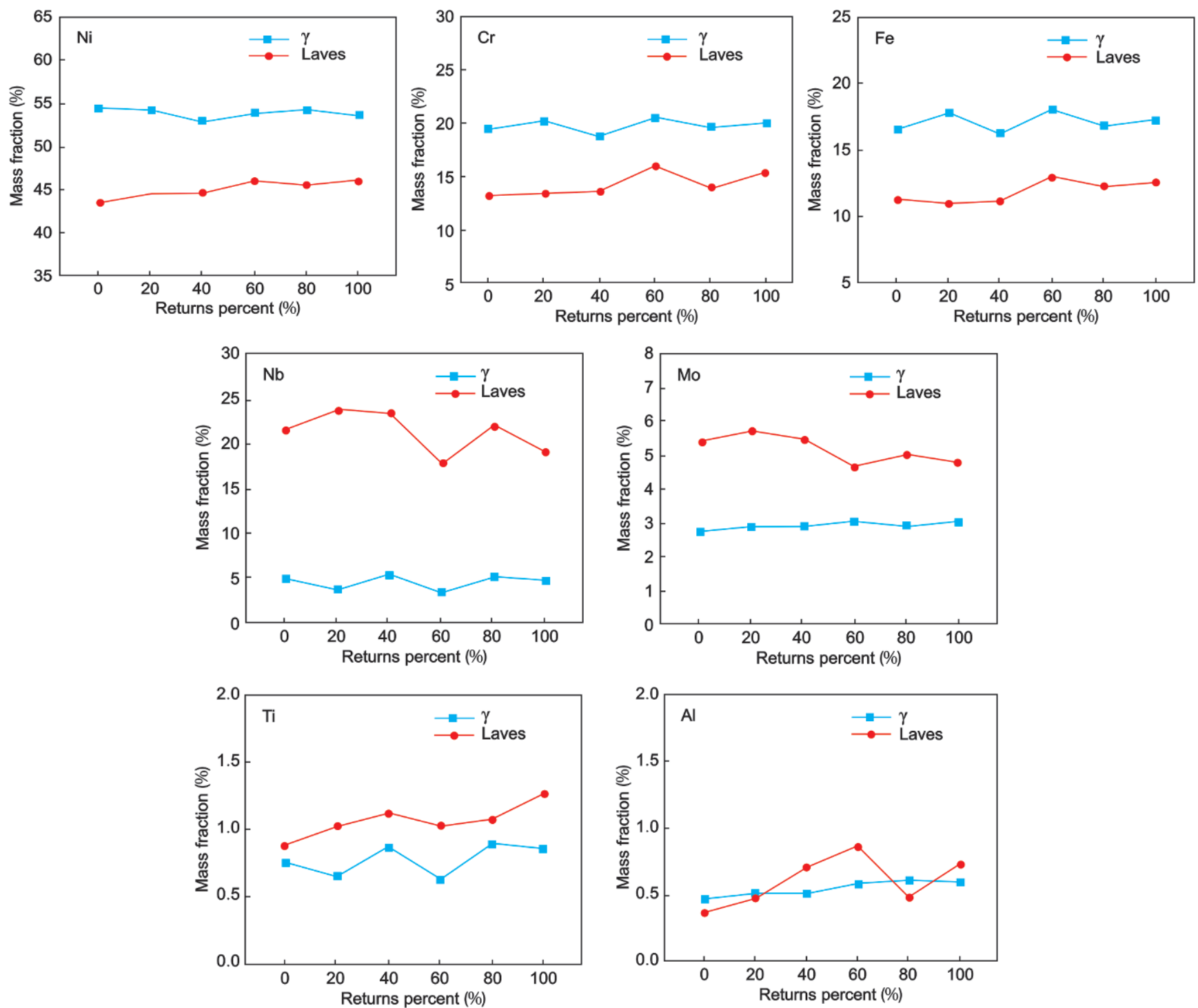

Fig. 2: Main element content in matrix $\gamma$ phase and Laves phase in GH4169 alloy with different proportions of returns

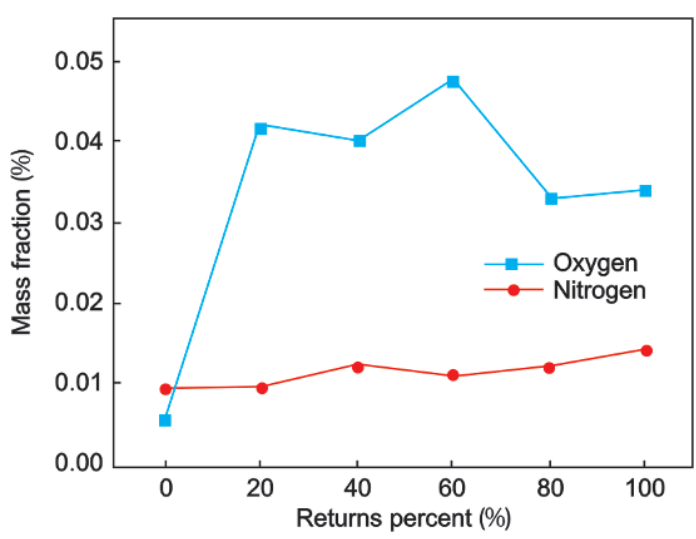

Fig. 3: Oxygen and nitrogen contents of GH4169 alloy with various proportions of returns

by Yu Qian and Zhang Hongwei ${ }^{[9,10]}$. The increment of oxygen content is much higher than nitrogen, and the fluctuation range of oxygen is also larger than nitrogen. Compared to the virgin alloy, the average contents of oxygen and nitrogen increase $603.57 \%$ and $24.55 \%$, respectively, for returns addition
GH4169 alloy. The maximum amount of oxygen appears in the alloy with $60 \%$ returns, and the maximum amount of nitrogen is found in the alloy with $100 \%$ returns.

\subsection{Effect of returns addition on microstructure}

The XRD patterns of returns addition GH4169 alloys are shown in Fig. 4. As the returns proportion in the alloy increases from 0 to $100 \%$, the precipitates are $(\mathrm{Fe}, \mathrm{Ni}), \mathrm{Ni}_{3}(\mathrm{Al}, \mathrm{Ti}), \mathrm{Ni}_{3} \mathrm{Nb}$ and $\mathrm{Ni}_{2} \mathrm{Nb}$, which are $\gamma, \gamma^{\prime}, \gamma^{\prime \prime}$ and Laves phase, respectively. Figure 5 shows the backscatter electron images of returns addition GH4169 alloy, and EDS results of Laves and oxide are given in Table 2. Besides the phases in XRD patterns, a globular phase, the oxide $\mathrm{Al}_{2} \mathrm{O}_{3}$, was found. Nevertheless, the nitride TiN was rarely found in various returns proportion alloys.

Figure 6 shows the precipitates of returns addition GH4169 alloys at room temperature. The white phase is Laves phase, and the black round phase is $\mathrm{Al}_{2} \mathrm{O}_{3}$ inclusion. The accumulation of Laves increases with an increase in returns from $0 \%$ to 


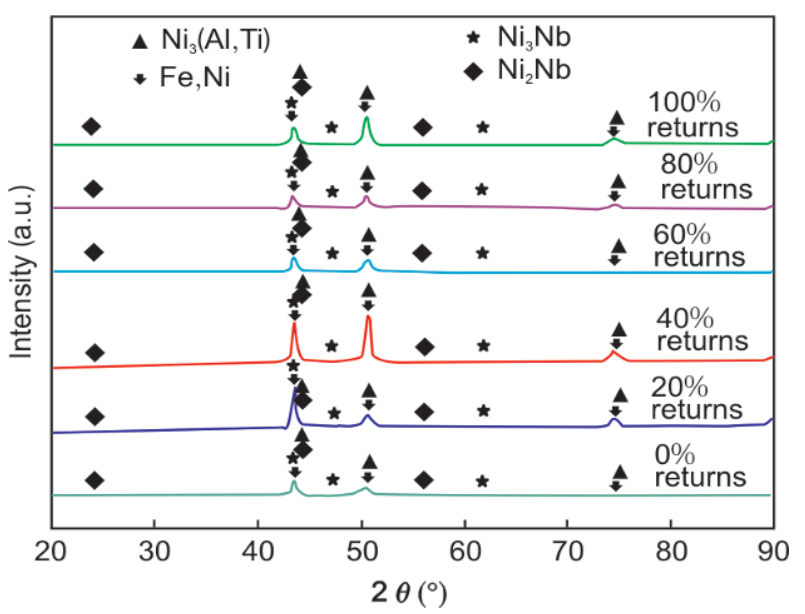

Fig. 4: XRD patterns of GH4169 samples with different proportions of returns

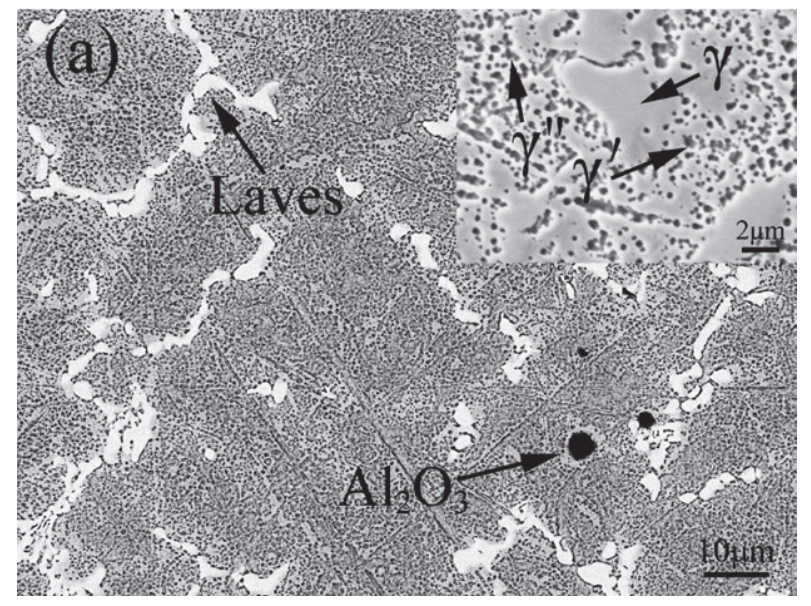

$60 \%$, and reaches the peak in the interdentritic region of the alloy with $60 \%$ returns. The $\mathrm{Al}_{2} \mathrm{O}_{3}$ inclusion shows the largest size in the alloy with $60 \%$ returns.

To further reveal the variation law of Laves and oxide $\left(\mathrm{Al}_{2} \mathrm{O}_{3}\right)$, the volume fraction and size of Laves and oxide are calculated from the statistical area on the cross section of all the GH4169 alloys with returns addition. Figure 7 shows that the maximum volume fraction of Laves is found in the alloy with $60 \%$ returns. Similarly, the maximum volume fraction and size of $\mathrm{Al}_{2} \mathrm{O}_{3}$ inclusion also exist in the alloy with $60 \%$ returns (Fig. 8). In other words, returns addition changes the volume fraction of Laves, and the volume fraction and size of $\mathrm{Al}_{2} \mathrm{O}_{3}$ inclusion, but the effect of returns proportion on the volume fraction and size of $\mathrm{Al}_{2} \mathrm{O}_{3}$ is still not obvious.

Fig. 5: Phases in GH4169 alloy with returns: (a) $20 \%$, (b) $100 \%$

Table 2: EDS compositions of Laves and oxide (at.\%)

\begin{tabular}{ccccccccccc} 
Phase & $\mathrm{Ni}$ & $\mathrm{Cr}$ & $\mathrm{Fe}$ & $\mathrm{Nb}$ & $\mathrm{Mo}$ & $\mathrm{Ti}$ & $\mathrm{Al}$ & $\mathbf{O}$ & $\mathbf{N}$ \\
\hline Laves & 40.57 & 10.91 & 9.62 & 20.17 & 6.87 & 1.58 & 0.71 & 9.58 & 0.0 \\
$\mathrm{Al}_{2} \mathrm{O}_{3}$ & 0.53 & 0.46 & 0.41 & 0.21 & 0.21 & 1.7 & 39.2 & 54.64 & 2.64 \\
\hline
\end{tabular}
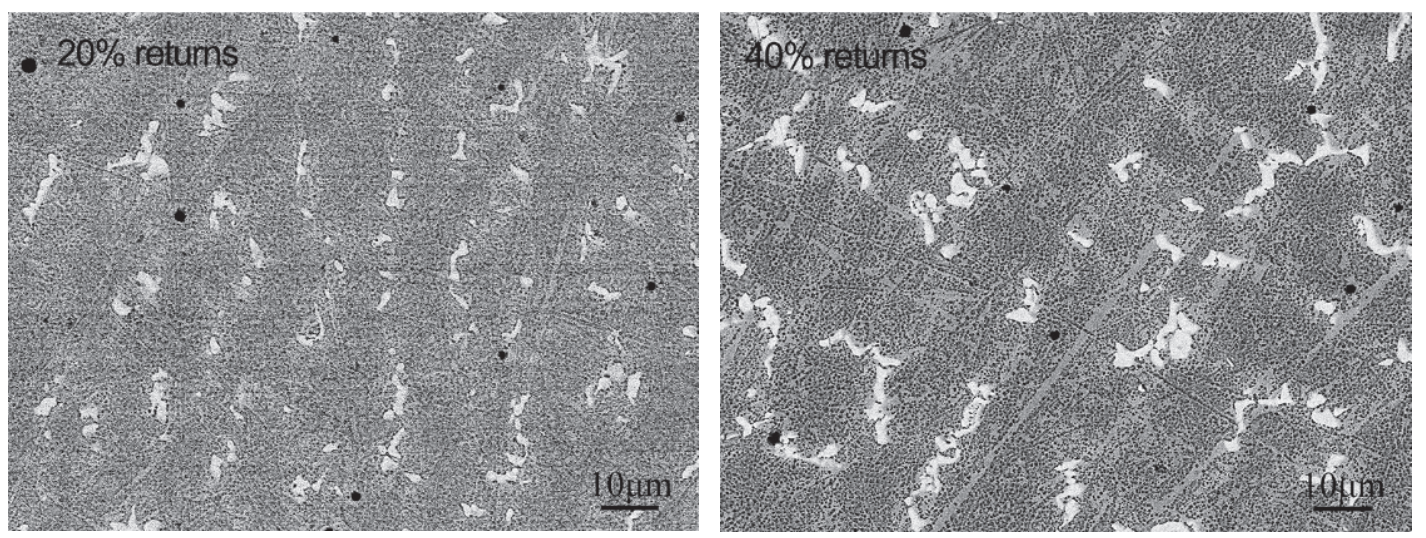

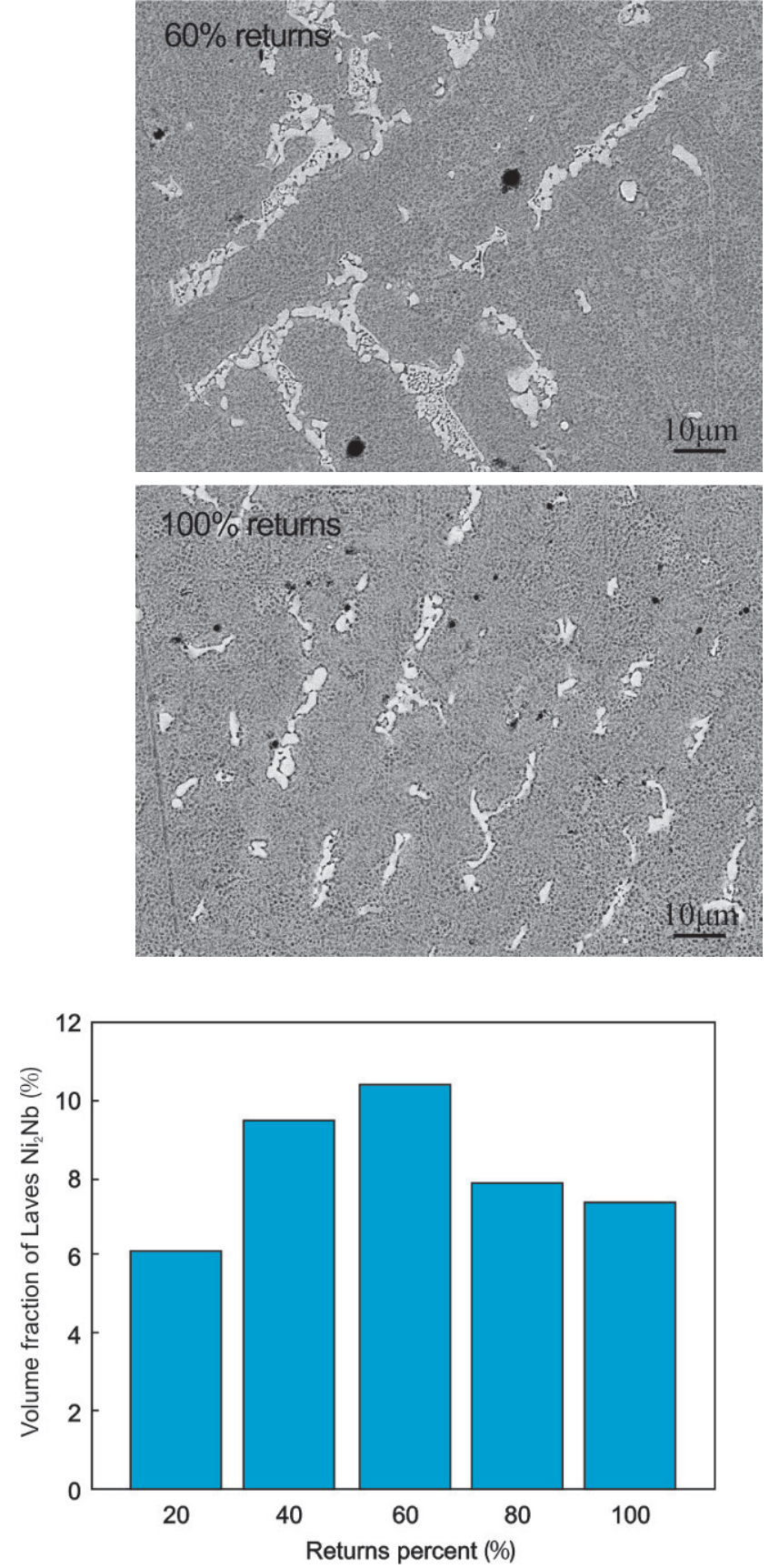

Fig. 7: Volume fraction of Laves in GH4169 alloy with various proportions of returns

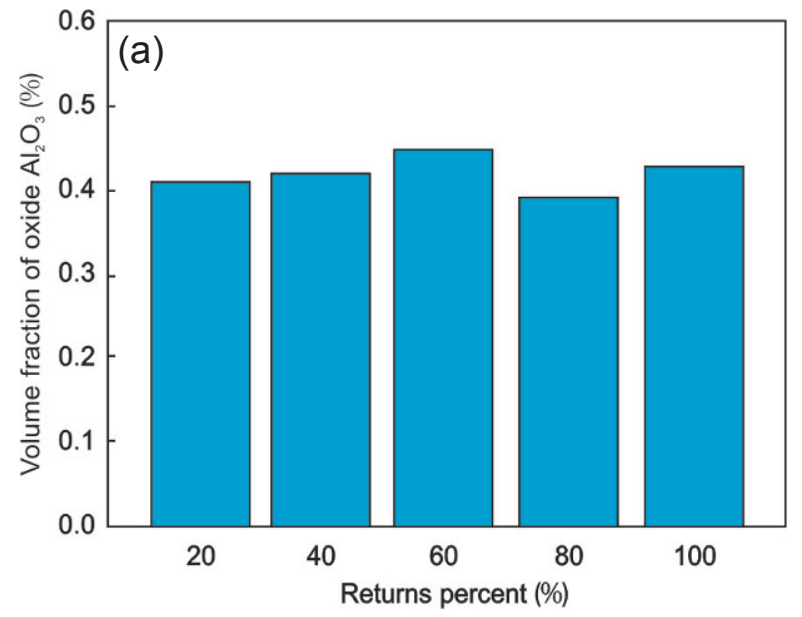

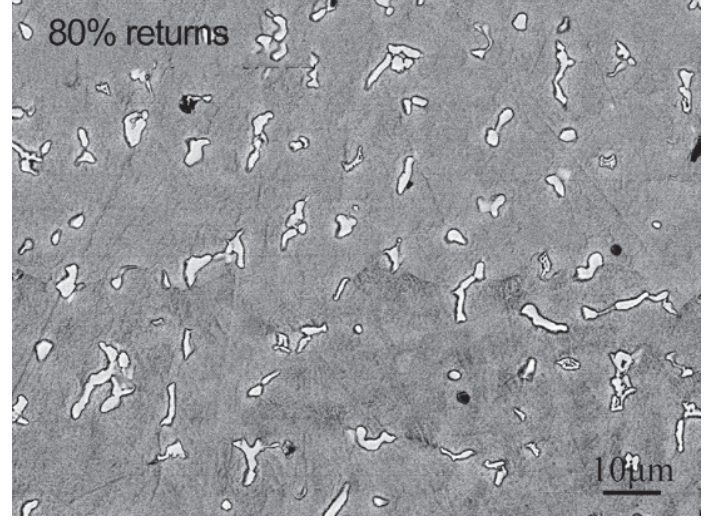

Fig. 6: Backscatter electron images of GH4169 alloy with various proportions of returns

\subsection{Effects of returns addition on mechanical properties}

The compression true stress vs. true strain curves of returns addition GH4169 alloy at room temperature and $1,150{ }^{\circ} \mathrm{C}$ are shown in Fig. 9. The curves of the alloys are close to each other with closed true strain value 1.2 under room temperature, indicating that the elastic and plastic deformation processes are similar for alloys with different returns proportions. At $1,150{ }^{\circ} \mathrm{C}$, except for the fracture shown in $40 \%$ returns proportion alloy, other samples experienced the elastic deformation, yield, stress soften and harden stages with the same true strain value 1.3, indicating that they have similar deformation process. Therefore, returns addition does not change the elastic and plastic deformation processes at room temperature or at $1,150{ }^{\circ} \mathrm{C}$.

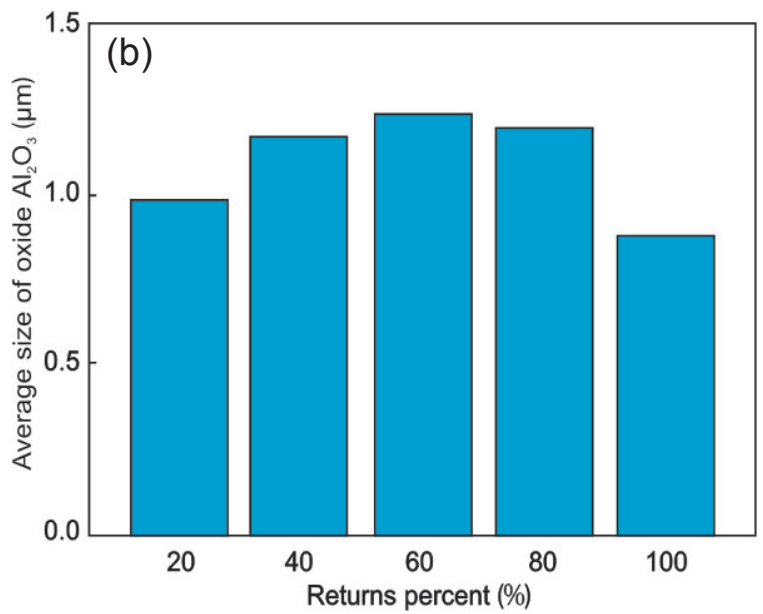

Fig. 8: Volume fraction and average size of $\mathrm{Al}_{2} \mathrm{O}_{3}$ in $\mathrm{GH} 4169$ alloy with various proportions of returns 

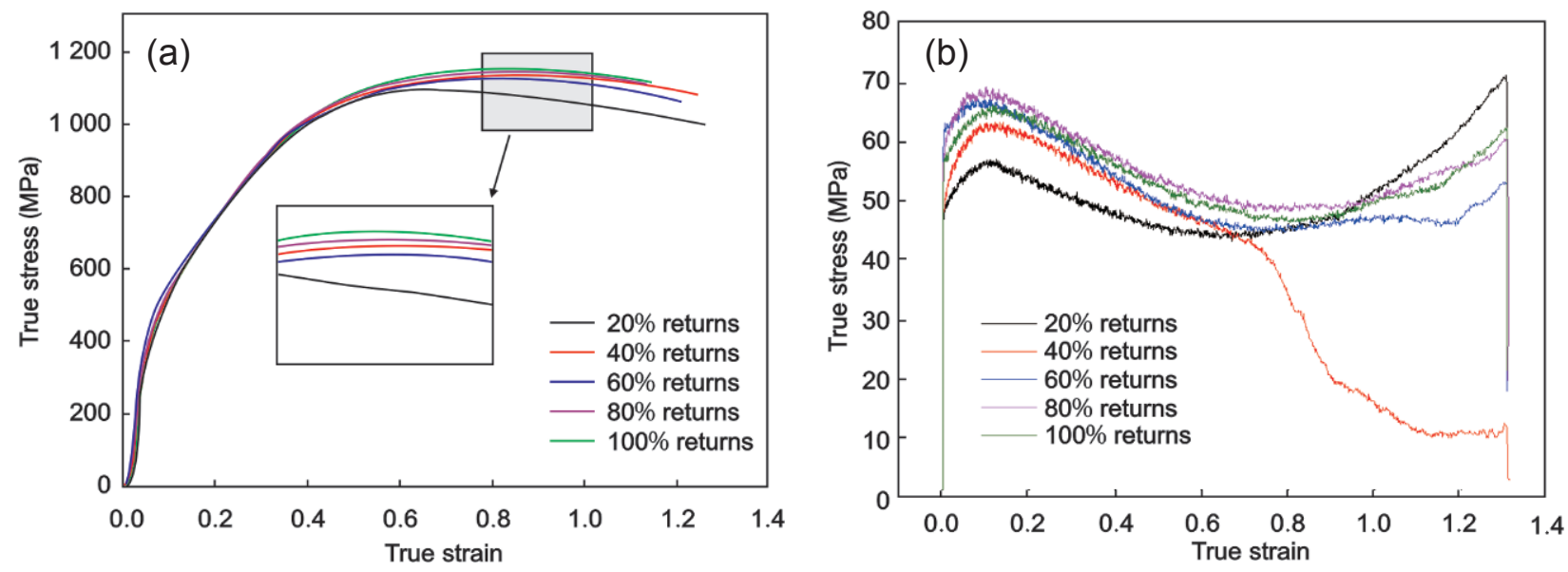

Fig. 9: True stress-true strain curves of various returns proportion GH4169 samples at different temperatures: (a) room temperature, (b) $1,150^{\circ} \mathrm{C}$

The compression strength and yield strength of the alloys are shown in Fig. 10. It clearly demonstrates that returns addition increases the compression strength and yield strength of GH4169 alloy. The 100 percent returns alloy shows the maximum value of compression strength $1153.45 \mathrm{MPa}$ at room temperature, while 80 percent returns alloy has the maximum value $69.3 \mathrm{MPa}$ at $1,150{ }^{\circ} \mathrm{C}$. It is noted that the 60 percent returns alloy shows both maximum values of yield strength, $516.65 \mathrm{MPa}$ at room temperature and $62.17 \mathrm{MPa}$ at $1,150{ }^{\circ} \mathrm{C}$ Moreover, yield strength and compression strength show larger fluctuation range at room temperature than at $1,150{ }^{\circ} \mathrm{C}$. The fluctuation ranges of yield strength and compression strength are 48.01 $\mathrm{MPa}$ and 55.27 $\mathrm{MPa}$ at room temperature, while they are 12.45 $\mathrm{MPa}$ and $12.18 \mathrm{MPa}$ at $1,150{ }^{\circ} \mathrm{C}$, respectively. Therefore, returns addition reduces the stability of compression properties of GH4169 alloy at room temperature.

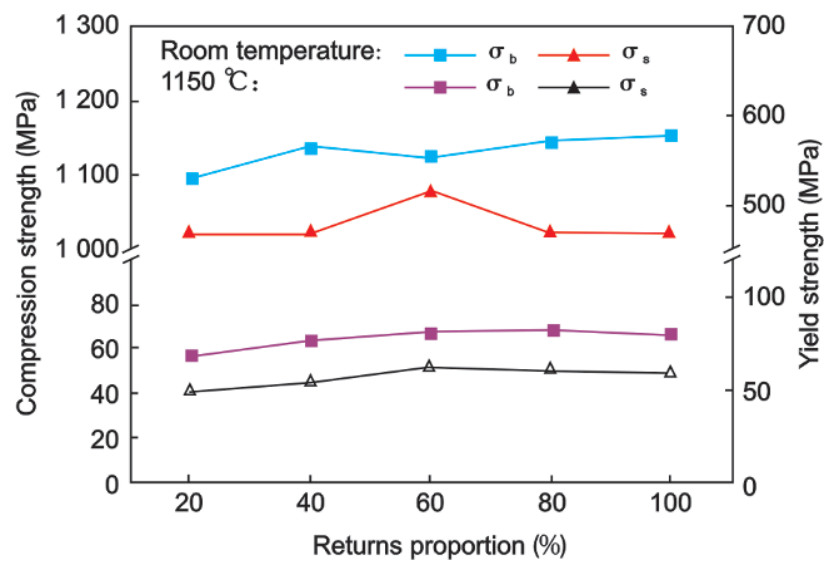

Fig. 10: Compression properties of various returns proportion GH4169 samples

For yield strength, the maximum value appears in $60 \%$ returns alloy at room temperature and $1,150{ }^{\circ} \mathrm{C}$. This is closely related to the microstructure change in $60 \%$ returns alloy. It is known from the microstructure that both the accumulation degree and the volume fraction of Laves phase are the largest in $60 \%$ returns alloy. The yield strength of GH4169 alloy can be described as a Hall-Petch relationship below:

$$
\sigma_{\mathrm{y}}=\sigma_{\mathrm{i}}+k d^{-n}
$$

where $\sigma_{\mathrm{y}}$ is the yield strength, the $\sigma_{\mathrm{i}}$ presents the stress opposing dislocation within a grain (including flow stress, dislocation reaction within a grain, etc.), $k d^{-n}$ relates to the pinning effect of grain boundary to the slide or dislocation movement, $d$ is the grain size, $k$ and $n$ are constant ${ }^{[15]}$. The yield strength is mainly influenced by the strength of $\gamma^{\prime \prime}$ precipitates, which is insignificantly influenced by the returns proportion due to the similar concentrations of major elements. The $\sigma_{\mathrm{i}}$ is not modified by the returns addition ${ }^{[16]}$. However, the Laves phase, distributed in the grain boundary and interdendritic regions, prevents the slide or movement of dislocation. The increased accumulation degree and raised volume fraction of Laves enhance the pinning effect of grain boundary, resulting in the increase of yield strength.

\section{Conclusions}

(1) Returns proportion has no significant effect on the main alloy elements content, but returns addition increases the levels of oxygen and nitrogen. The increment of oxygen is much higher than nitrogen. The average increase of oxygen is $603.57 \%$ for various returns addition alloy, while the average increase of nitrogen is only $24.55 \%$.

(2) Returns proportion has no obvious influence on the principle precipitates. However, returns addition increases the volume fraction and the size of $\mathrm{Al}_{2} \mathrm{O}_{3}$ inclusion, and the accumulation level and volume fraction of Laves phase are also increased. The fraction and size of $\mathrm{Al}_{2} \mathrm{O}_{3}$ inclusion, and the fraction of Laves reach the maximum values in $60 \%$ returns proportion GH4169 alloy.

(3) Returns addition does not change the elastic and plastic deformation process at room temperature or at $1,150{ }^{\circ} \mathrm{C}$, but high returns proportion GH4169 alloy shows improved compression strength and yield strength. The 100\% returns alloy shows the maximum value of compression strength 1153.45 $\mathrm{MPa}$ at room temperature, while $80 \%$ returns alloy 
has the maximum value $69.3 \mathrm{MPa}$ at $1,150{ }^{\circ} \mathrm{C}$. It is noted that the $60 \%$ returns alloy shows both maximum values of yield strength, 516.65 $\mathrm{MPa}$ at room temperature and $62.17 \mathrm{MPa}$ at $1,150{ }^{\circ} \mathrm{C}$.

(4) Returns addition increases the instability of the compression properties of GH4169 alloy at room temperature. Yield strength and compression strength show larger fluctuation range at room temperature. The fluctuation ranges of yield strength and compression strength are 48.01 MPa and 55.27 $\mathrm{MPa}$ at room temperature, while they are $12.45 \mathrm{MPa}$ and 12.18 $\mathrm{MPa}$ at $1,150^{\circ} \mathrm{C}$, respectively.

(5) Returns addition mainly increases the volume fraction of $\mathrm{Al}_{2} \mathrm{O}_{3}$ inclusion, resulting in the increase of oxygen level of GH4169 alloy. At the same time, the accumulation of Laves phase increases in the interdendritic regions. The fraction volume and the size of $\mathrm{Al}_{2} \mathrm{O}_{3}$ inclusion and the fraction of Laves phase reach the maximum values in the alloy with $60 \%$ returns, resulting in the maximum value of yield strength at both room temperature and $1,150{ }^{\circ} \mathrm{C}$.

\section{References}

[1] Yan Minggao. China Aeronautical Materials Handbook. 2nd ed. Beijing: China Standard Press, 2002: 323-325. (In Chinese)

[2] Yuan Chao, Guo Jianting, Wang Tieli, et al. Effect of revert proportion on microstructure and property of a cast cobaltbased superalloy K640S. Acta Metallurgica Sinica, 2000, 36(9): 961-965. (In Chinese)

[3] Wang Tieli, Cui Tong, Yang Hongcai, et al. Effect of revert recycle times on microstructure and thermal fatigue properties in cobalt-base superalloy K640S. Journal of Northeastern University (Natural Science), 2003, 24(6): 580-582. (In Chinese)

[4] Li Zhijun, Zhou Lanzhang, Guo Jianting. Effect of revert proportion on microstructure and mechanical properties of superalloy K444. Eleventh China Superalloys Congress. Beijing: Metallurgical Industry Press, 2007: 331-335. (In Chinese)
[5] Wang Dinggang, Song Jinxia, Xiao Chengbo, et al. Effect of recycle times on microstructures and mechanical properties of Ni-base superalloy K465. Ordnance Material Science and Engineering, 2014, 37(4): 98-101. (In Chinese)

[6] Chen Zhuo, Zhen Baolin, Chen Jiazhi, et al. Effect of recycle times of revert on composition and mechanical properties of K424 alloy. Journal of Iron and Steel Research, 2006, 18(4): 44-47. (In Chinese)

[7] Man Yanlin, Wang Yufei, Wang Xinya, et al. Effect of returns smelting on structure and mechanical properties of K414 alloy. Foundry, 2013, 62(7): 666-669. (In Chinese)

[8] Man Yanlin, Wang Yufei, Yang Gang, et al. Effect of Revert Recycle Times on Microstructure and Mechanical Properties of Ni-Based Superalloy K4169. Chinese Journal of Rare Metals, 2012, 36(1): 54-60. (In Chinese)

[9] Yu Qian, Song Jinxia, Wang Dinggang, et al. Effect of Recycled alloy proportion on microstructure and mechanical properties of $\mathrm{Ni}$ based superalloy K465. Journal of Materials Engineering, 2006, (6): 9-12. (In Chinese)

[10] Zhang Hongwei. Effect of revert proportion on chemical compositions and creep-rupture properties of K4002 superalloy. Aerospace Manufacturing Technology, 2006, (6): 35-37.

[11] Li Zhijun, Zhou Lanzhang, Guo Jianting, et al. Effect of revert proportion on thermal fatigue properties of K44 superalloy. Journal of Materials Engineering, 2005, (8): 24-27. (In Chinese)

[12] Wang Yufei, Man Yanlin, Yang Gang, et al. Effect of revert proportion on chemical compositions and mechanical properties of K414 superalloy. Foundry, 2012, 61(3): 320-323. (In Chinese)

[13] Miao Zhujun. Study on solidification segregation and homogenization treatments of IN718-type superalloys. Shanghai: Shang Hai Jiao Tong University, 2011: 43-47. (In Chinese)

[14] Kuo Kehsin. Phases in high alloy steels and superalloys. Acta Metallurgica Sinica, 1978, 14(1): 73-95. (In Chinese)

[15] Zhou P J, Yu J J, Sun X F, et al. The role of boron on a conventional nickel-based superalloy. Materials Science and Engineering A, 2008, 491(1): 159-163.

[16] Yang Y H, Yu J J, Sun X F,et al. Effect of revert addition on microstructure and mechanical properties of M951 Ni-base superalloy. Materials Science and Engineering A, 2012(532): 6-12. 